\title{
La lucha contra las enfermedades infecciosas de los niños en la Región de Magallanes, Chile. Muerte, pasión y vida (Parte I)
}

\begin{abstract}
Matías Vieira
\author{
Struggle against infectious diseases in children in the Magallanes Region. \\ Death, passion and life (Part I)
}

Historical background of infectious diseases of children in the Region of Magallanes is reviewed, with special emphasis on their impact on infant mortality. For purposes of publication, the research is divided into two parts. In this first one, we present a brief relation of the facts that led to the death of almost all of the Spanish colonizers of the Strait of Magellan, including children (1584-1590); following, a description of the available data on infectious diseases affecting Patagonian Indians before contact with white man. Finally we describe the health situation in Punta Arenas, from the foundation of Bulnes Fort until the end of the 19th century.

Key words: Patagonia, Magallanes Region, history, childhood infectious diseases, Pedro Sarmiento de Gamboa, Patagonian Indians, history of Punta Arenas.

Palabras clave: Patagonia, Región de Magallanes, historia, enfermedades infecciosas infantiles, Pedro Sarmiento de Gamboa, aborígenes australes, historia de Punta Arenas.

\section{EI fracaso de Sarmiento de Gamboa: pocos niños, muchas muertes}

$\mathrm{P}$ edro Sarmiento de Gamboa (Figura 1) había sido enviado por el Virrey del Perú en 1580, con la misión de perseguir al corsario Drake, y de pasada explorar el Estrecho de Magallanes. A Drake no lo encontró, pero se obsesionó con la idea de poblar las márgenes del Estrecho, y se presentó ante el Rey Felipe II en busca de apoyo y financiamiento para esta empresa. Así fue como a fines de 1581 se preparó una escuadra como pocas veces vista: zarparon finalmente de España veintitrés navíos con tres mil personas, entre los cuales iban -o venían- soldados, marineros, oficiales, clérigos, letrados y familias completas, pero aparte de un barbero, quien por lo demás desertó en Río de Janeiro, no se sabe del embarque de ningún médico. En cuanto a medicinas, solamente consta la presencia de dos bultos, a todas luces insuficiente para la envergadura de la empresa y los años que permanecerían en ella ${ }^{1,2}$.

Las desgracias de Sarmiento, quien valga decir que no iba como jefe de la expedición sino como Capitán General del Estrecho de Magallanes y Gobernador de lo que en él se poblare, se comenzaron a desencadenar en este viaje. Resumiré diciendo que entre vendavales, naufragios, escorbuto y pestes, abandonos y traiciones, poco más de dos años después de zarpar de España, ingresaron al estrecho sólo cinco naves y unas quinientas personas ${ }^{1,2}$.
Como broche final de la llegada de los restos de esta flota, habiendo alcanzado hasta la bahía de San Gregorio, una tempestad los hizo retroceder y por poco no los arrojó nuevamente hasta el Atlántico. Es ahí que Sarmiento, probablemente presionado por la desesperación de su gente y de su propia desazón que llegaba al límite de lo humanamente sostenible, decidió fundar -en forma que se demostraría apresurada-, muy próxima a la boca oriental -probablemente en la hoy Punta Dungeness- del Estrecho de Todos los Santos, o de Magallanes, la Ciudad del Nombre de Jesús ${ }^{2}$.

En sus inicios (1584) la población constaba de ciento ochenta y tres soldados, sesenta y ocho pobladores va-

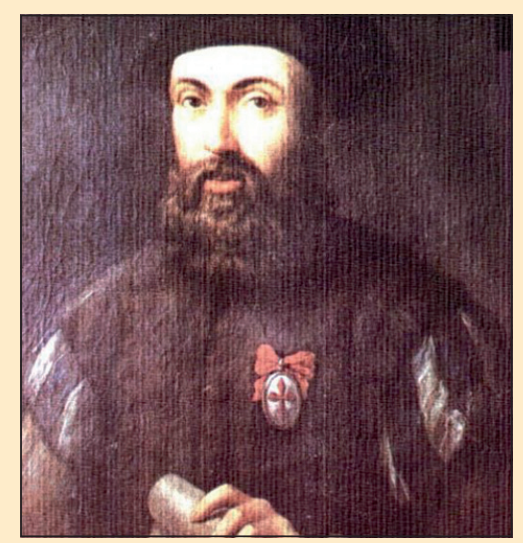

Figura 1. Pedro Sarmiento de Gamboa.
Hospital Clínico de Magallanes Dr. Lautaro Navarro Avaria. Servicio de Salud Magallanes. Unidad de Patrimonio Cultural

Recibido: 3 de octubre de 2013

Correspondencia a:

Matías Vieira G.

matvi46@gmail.com 
rones, trece mujeres, once niños y dos negros. Entre los colonos quedaban dos frailes, y como hemos dicho, no venía ningún médico. Se construyó, eso sí, un rudimentario hospital. Los mencionados niños terminarían por engrosar la mortalidad infantil de Magallanes, que a la sazón llegó a 100\% entre los hijos de los colonizadores europeos. Claro es que no sólo murieron los niños, sino también casi todos los adultos, en una tragedia que duró seis años, contados hasta el rescate del último de los dos únicos sobrevivientes. Las causas de estas muertes están en algunos casos bien establecidas, pero en la mayoría no se pasa de meras conjeturas. Qué incidencia tuvieron en ellas las enfermedades infecciosas, es algo difícil de determinar ${ }^{2}$.

En lo que interesa para esta revisión, cabe destacar que a la fecha del zarpe de España cundía por el continente europeo una pandemia de influenza con alta mortalidad llamada Gran Catarro, de la cual no sobrevivió ni la reina, y el Rey Felipe II estuvo a punto de sucumbir. No hay registro de enfermos entre los embarcados, aunque es de toda lógica pensar que habría más de algún afectado, durante o previo al viaje. Hay quienes postulan que dicha virosis pudo provocar un estado de debilidad tal sobre individuos crónicamente desnutridos, que pudo ser determinante en la mortandad de los colonos en el Estrecho de Magallanes. No obstante, es médicamente poco sostenible que la influenza tenga secuelas tan tardías ${ }^{2,3}$.

También se presentaba por aquellos años en España un brote de peste, que corresponde a la peste bubónica, esencialmente transmitida por las pulgas de ratas. Sin embargo, ni los detallados informes posteriores de Sarmiento, ni del sobreviviente Tomé Hernández parecen dar cuenta de esta enfermedad que hubiese sido fácilmente reconocible. Por otro lado y de ser así, su persistencia hubiera sido muy poco probable, puesto que es sabido que en Magallanes las pulgas no sobreviven ${ }^{2,3}$.

Estudios de osamentas encontradas en uno de los sitios en que pudo haber estado Nombre de Jesús, entre las cuales se cuenta la de un niño de aproximadamente doce años, muestran signos de osteoporosis probablemente secundaria a carencias nutricionales. Lo más llamativo son los signos de infecciones óseas, no bien especificadas. Tal vez osteomielitis bacteriana, o más seguramente tuberculosis ${ }^{2,3}$.

Dos meses después de la fundación de la primera ciudad, y tras una penosa marcha de más de trescientos kilómetros, con sólo cincuenta embarcados en la única nave que les quedaba, Sarmiento funda en Bahía Buena la Ciudad del Rey Don Felipe, la cual también contó con hospital. Dicho sea de paso, éstos fueron los dos primeros hospitales de la futura Región de Magallanes. Los niños probablemente habían quedado casi todos en Nombre de Jesús, aunque algún cronista habla de que en el duro invierno que siguió (desde fines de abril les nevó durante doce días seguidos), el pan en Rey Felipe se daba sólo a los niños y enfermos ${ }^{1,2}$.

En distintas publicaciones han sido barajadas otras causas de muertes. Descartamos de plano la leyenda de la muerte por inanición. Sarmiento describe la abundancia de recursos prácticamente al alcance de la mano, como caza de venados (probablemente huemules) y lobos marinos, mariscos, frutos silvestres, pesca. Algunos pasajes, de tanto su relato como el de Tomé Hernández, describen algunos períodos de hambruna, tanto que hubo un caso de canibalismo, pero parecen haber sido los menos. En la marcha de Nombre de Jesús a Rey don Felipe debieron comerse las cabras y los perros, pero ninguno murió de hambre. En los largos meses de invierno el procurar alimentos se hacía más difícil, especialmente por desconocimiento de la zona, y hubo algunos, los menos, que murieron efectivamente de hambre. Hubo muertes violentas por ataques de indígenas, accidentes, homicidios y ajusticiamientos. Es muy probable que, al menos en algunos casos, la hipotermia haya sido la causa determinante de muerte. Por último, la intoxicación por marea roja ofrece un cuadro clínico atrozmente catastrófico, y difícilmente pudo haber pasado sin otorgársele la debida importancia en los relatos de los sobrevivientes ${ }^{2}$.

A los dos meses de haber fundado Rey Don Felipe, Pedro Sarmiento se embarcó con la idea de regresar a Nombre de Jesús, pero al aproximarse al Atlántico lo sorprendió una tormenta que terminó por forzarlo a navegar hasta Río de Janeiro. Pasó el resto de su vida obsesionado por la idea de volver a rescatar a sus compañeros, pero nunca lo logró. Estos últimos fueron muriendo, a consecuencia de violencias, frío y dolencias no bien precisadas. Las enfermedades infecciosas que pudieron haber traído de España, como viruela o tuberculosis, no aparecen descritas en las publicaciones revisadas, con excepción del dato arqueológico de aquellas de las infecciones óseas. Es de común conocimiento que el clima frío patagónico austral es poco favorable a la propagación de dolencias infecciosas. No existen insectos vectores. Claro, algunos habrán fallecido de enfermedades, pero fueron sin duda los menos. Entre los niños probablemente hizo estragos la alimentación inadecuada, pobre en vegetales, leche y vitaminas. Lo cierto es que a los dos años desde la fundación de Nombre de Jesús ya habían muerto todos los niños, vagando de un lado a otro unas veinte personas, incluyendo tres mujeres. Entre los adultos, si no la mayoría, por los menos una buena parte debió sucumbir ante la desazón de sentirse abandonados, sin voluntad para luchar, muriendo de desesperanza ${ }^{2}$.

\section{Nuestros primeros padres: los aborígenes}

Hace trece o catorce mil años el Estrecho de Magallanes formaba parte de un gigantesco glaciar, y entre el 
hielo y el archipiélago oriental, conformado por las islas Magdalena, Marta, Isabel y Contramaestre, se formaba un gran puente entre el continente y la Isla de Tierra del Fuego. Por aquí, y hay vestigios arqueológicos en las islas que así lo demuestran, y también probablemente por la Primera Angostura, migraron inicialmente los Haush. Más adelante éstos fueron desplazados por los Selknam u Onas hacia el cabo más suroriental de la isla (Figura 2). Al retirarse el glaciar, quedaron estos pueblos literalmente aislados, pero libres de errar por los miles de kilómetros de su prisión geográfica. En el continente, y especialmente por sus estepas, quedaron los Aonikenk, Patagones o Tehuelches, cuyos dominios territoriales abarcaban gran parte de la Patagonia continental, llegando a confundirse hacia el norte con los mapuches del este de la Cordillera de los Andes. Estos tres pueblos eran cazadores y recolectores. Los pueblos canoeros habitaban entre las miles de islas que en el extremo sur desgranan nuestra geografía: los Kaweskar o Alacalufes hacia el norte, y los Yámanas o Yaganes hacia el sur. Lo anteriormente dicho no es plenamente exacto, pues hay evidencias y observaciones desde por lo menos el siglo XIX, hechas por expedicionarios europeos, de la imbricación entre estos pueblos, tanto social como territorialmente. Sin embargo, para los efectos de esta revisión, baste con la simplificación antes enunciada ${ }^{6}$.

Cuando el portugués Fernao de Magalhaes, al servicio de la corona de España, pasó por el estrecho que luego llevaría su nombre, se encontró con estas gentes en apariencia muy primitivos, y que habían vivido en la edad de piedra durante milenios, por lo que es de suponer que sus usos, creencias y costumbres no habían variado mayormente en este enorme lapso. No habiendo habido adelantos tecnológicos ni científicos, ni escritura de ningún tipo, los conocimientos $\mathrm{y}$ patrones de conducta se transmitían de padres a hijos, sin variaciones de importancia con el paso de las generaciones. Todo cambió, por supuesto, con la llegada de los hombres blancos. Los exploradores de comienzos del siglo XIX, y luego los misioneros, tanto anglicanos como católicos, a fines del siglo XIX y comienzos XX ya se habían interesado por estudiar sus costumbres, y se encontraron con un material prácticamente impoluto, por lo que las descripciones de religiosos como el anglicano Thomas Bridges (Figura 3) y su hijo Lucas, el sacerdote alemán Martín Gusinde (Figura 4), el sacerdote italiano Alberto De Agostini y otros, debieron ser un bastante fiel reflejo de una antropología de siglos de no haber evolucionado mayormente ${ }^{6}$.

Habida consideración de lo dicho, volvemos a los nuestro:

Desde el punto de vista pediátrico, no tan malos fueron los resultados de las costumbres aborígenes, ya que algunos niños sobrevivían pese a la extrema rigurosidad del clima. No disponemos, obviamente, de indicadores de salud ni datos estadísticos de mortalidad infantil de aquellas épocas. Sabemos que ésta era alta y que el número de habitantes tendía a mantenerse estacionario. En todo caso es de presumir que el contacto con el hombre blanco empeoró las cosas, puesto que éste inicialmente no trajo adelantos médicos sino nuevas y desconocidas enfermedades. No hemos encontrado descripciones especialmente rigurosas respecto a las enfermedades que afectaban a los niños, ni menos si éstas eran o no de origen infeccioso. Los observadores se abocaron más a las descripciones de los métodos de sanación, especialmente a lo atingente a la espectacularidad y parafernalia de los curanderos más que a las enfermedades mismas. Parece ser, en todo caso, que las patologías infectocontagiosas que diezmaban a la infancia en el resto de América, y por qué no, del mundo "civilizado", como la tuberculosis, el sarampión, la viruela, el coqueluche, no existían entre los pueblos originarios de Magallanes ${ }^{4,5,8}$.

Pero de que existieron infecciones, si bien probablemente no contagiosas, es claro que sí existieron. Así lo demuestran los restos óseos, especialmente los conservados en el Centro de Estudios del Hombre Austral, dependiente de la Universidad de Magallanes. En ellos se encuentran fundamentalmente evidencias de carencias nutricionales y de traumatismos, pero también de osteoartritis, osteomielitis y de mastoiditis. Contaban con una extensa farmacopea aborigen, que no es del caso relatar aquí, complementadas con aceites de pescado o grasas animales para ungüentos y pócimas. Para las infecciones óticas se goteaba aceite de pescado caliente en el conducto auditivo, el que en el caso de los infantes se reemplazaba por leche materna. Si estos remedios no resultaban, se recurría al curandero y sus magias ${ }^{4,5}$.

Obviando otras consideraciones, todas las tribus patagónicas eran de costumbres más bien pacíficas. No abundaré, por no corresponder a esta revisión, en sus hábitos y creencias. Sólo recalcaré que las familias eran en general bien constituidas. (Algunas poligámicas, pero bien

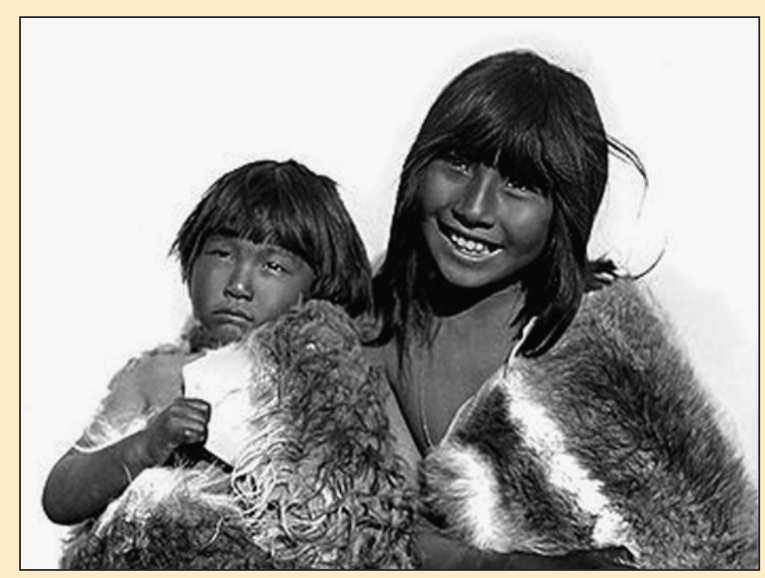

Figura 2. Niños Selknam. 


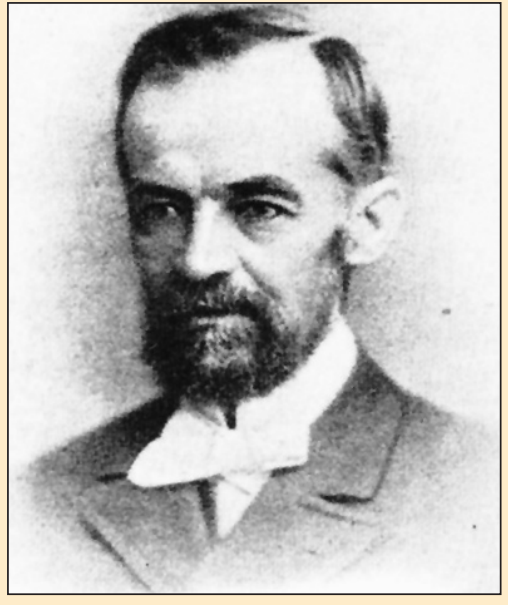

Figura 3. Misionero anglicano Thomas Bridges.

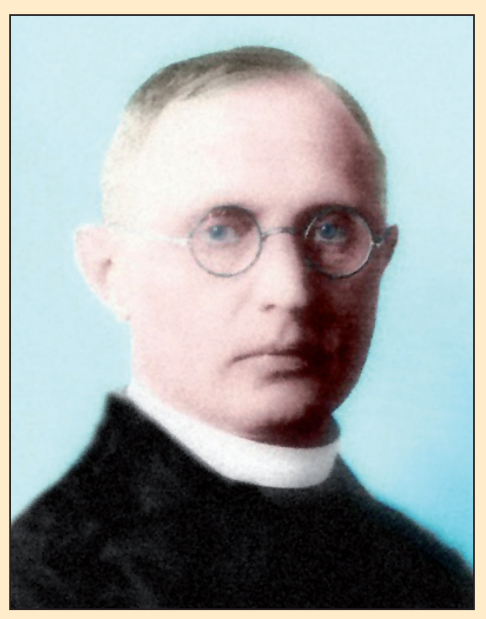

Figura 4. Sacerdote católico Martín Gusinde. constituidas). Los niños eran amados y muy bien tratados. $\mathrm{Al}$ decir de Gusinde: Cuando se oye que un niño grita es que le duele algo. Es inútil decir que no es desconocida entre nuestros indios la mortalidad infantil. La cifra media de la misma se mantiene considerablemente alta, aunque en comparación son muchas las familias de alli que se encuentran agraciadas con muchos hijos. Respecto a lo mismo, señalaba el jurista y escritor Robustiano Vera en libro publicado en 1897: (...) por regla general, las mujeres tienen siete u ocho hijos i muchas veces se puede encontrar otras que, aunque bastante jóvenes, tienen ya diez o doce. El hecho de que haya pocos niños que sobrevivan a los padres, hai que atribuirlo a la mortalidad entre los niños de 2 a 10 años, que es verdaderamente extraordinaria ${ }^{6,7,8}$.

Desde fines del siglo XVI hasta mediados del XIX surcaron aguas australes una serie de naves de diversas nacionalidades europeas: algunas con afán científico, levantamiento de mapas y cartas hidrográficas, mera exploración, o con intenciones más lucrativas, como los balleneros y foqueros. Otras tomaron contacto más o menos prolongado con los indígenas, llevándose pieles y dejando la sífilis. Parece ser, en todo caso, que no alcanzaron provocar mayor mella en las costumbres tradicionales aborígenes.

En la segunda parte de esta revisión nos referiremos al modo en que enfermaron y murieron cientos de niños indígenas, afectados por las enfermedades infectocontagiosas aportadas por el hombre blanco.

\section{Del Fuerte Bulnes a Sandy Point: sanación por el frío}

Sin duda es la expedición de la Goleta Ancud, ya bien establecida la República, el primer intento que logra con buen éxito iniciar la colonización de estos territorios. Sin embargo, tampoco en esta notable empresa, que concluyó con la toma de posesión del Estrecho de Magallanes y la fundación de Fuerte Bulnes en 1843, venía ningún médico, ni menos un pediatra, pese a que en ella se embarcó a un niño. Recién al año siguiente, junto con un capellán, sesenta hombres de una compañía de artillería, varios reos y otros colonos, llega el primer médico: el cirujano José María Betelú. En ese momento una de las dependencias del fuerte, un rancho construido con paredes de "champa" y techo de paja, pasó a cumplir las funciones de improvisado hospital. La preparación profesional de Betelú, al decir de Mateo Martinic, no debió pasar más allá de la que podría poseer un "buenpráctico" de la medicina, con algunos estudios y experiencias. Los tiempos fueron duros, especialmente en invierno. Había madera en abundancia, pero los turbales no eran aptos para cultivos ni para la cría de ganado. Para colmo de males, un incendio arrasó con gran parte de las construcciones. Es así como, en 1848, el Gobernador José de los Santos Mardones decide trasladar la colonia sesenta kilómetros más al norte, a un lugar llamado Sandy Point ${ }^{8,9}$ (Figura 5 y 6).

Estos hechos se sucedieron durante la presidencia de don Manuel Bulnes. Con el gobierno de don Manuel Montt (1851-1861) se constituye formalmente la Colonia de Magallanes, la que pasó a ser, por un tiempo, más un centro de reclusión que de colonización. En sus comienzos eran pocos los valientes que se aventuraban a establecerse con sus familias a intentar labrarse honradamente un futuro de dignidad y prosperidad. A partir de 1853 pasó a ser zona colonizadora, y los gobiernos impulsaron, con diversas franquicias, la llegada de gente que quisiera instalarse en estas tierras. Como uno de los anzuelos se promocionaba la benignidad del clima. Así por ejemplo, el Gobernador Jorge Schythe informaba:... el temperamento (clima) es benigno, considerando la 
latitud, saludable y vivificante. Más tarde el Gobernador Oscar Viel escribía que la colonia poseía... inmejorable clima, no conociéndose epidemia alguna como las que diezman a la República Argentina. En 1883 el Gobernador Francisco Sampaio informaba al Supremo Gobierno: $L a$ temperatura es regularmente benigna y tan sana, que son del todo desconocidas las enfermedades epidémicas, y sin que hasta la fecha se haya notado ninguna contagiosa. Contemporáneamente, el irlandés Thomas Fenton (Figura 7), primer médico con título universitario que ejerció en la colonia, manifestaba: El clima de este Territorio es uno de los más hijiénicos que se puede conocer; sobre todo, la estación de verano favorece en mucho a los enfermos de tisis, bronquitis, tercianas $i$ disentería, y agregaba que favorecía el buen resultado de los tratamientos, $i$ mui especialmente en los niños. En su libro de 1897, refrendaba también Robustiano Vera:... poco a poco tendrá que ser el centro de un emigración voluntaria, por más que se diga que su clima es frío, único ataque que se puede hacer, por los que no conocen esas localidades. Mas a éstos respondemos que no por eso deja de ser sano, puesto que no hai alli pestes ni enfermedades que hagan peligrar la vida de sus moradores. Léjos de eso, su clima es inmejorable para ciertas enfermedades, como ser las del hígado i del pulmón ${ }^{8,9}$.

No escapaba sin embargo a las autoridades sanitarias el precario saneamiento ambiental, materia que estuvo en la palestra pública durante toda la segunda mitad del siglo XIX. Hacia 1855 el Gobernador Jorge Schythe dictó una serie de prohibiciones para los habitantes de la colonia, entre las cuales destacan: Prohibición de lavar ropa i útiles de cocina o votar inmundicias en el rio de Punta Arenas del puente para arriba, por ser este rio de donde se toma el agua potable, bajo multa de \$2. A los habitantes de las casas de la calle principal se les prohibía arrojar en ella agua, basuras o inmundicias, bajo multa de 1 a 3 pesos ${ }^{8}$.

Según refiere Mateo Martinic en su hermoso libro "La Medicina en Magallanes", en 1875 el Gobernador Diego Dublé Almeyda preparaba un Reglamento de Policía, con una serie de normas y prohibiciones para mejorar la higiene ambiental, puesto que, entre otras cosas, Era propio también de los hábitos vecinales de entonces, como lo sería también por largo tiempo, el arrojar aguas servidas a la calle, que al quedar apozadas en acequias se descomponian dejando en el aire ambiente un hedor característico, más perceptible en los días calmos, lo que molestaba especialmente a los visitantes extraños ${ }^{9}$.

Hacia fines de siglo, Robustiano Vera, en su libro que mucho alababa la benignidad del clima, acotaba: El agua que se consume por sus habitantes está corrompida por las filtraciones a causa de las letrinas de las casas, las que de ordinario están cerca de los pozos de donde se estrae el agua que se bebe. Se espera en esa ciudad pestes i toda clase de enfermedades. El Médico de Ciudad Dr. Lautaro

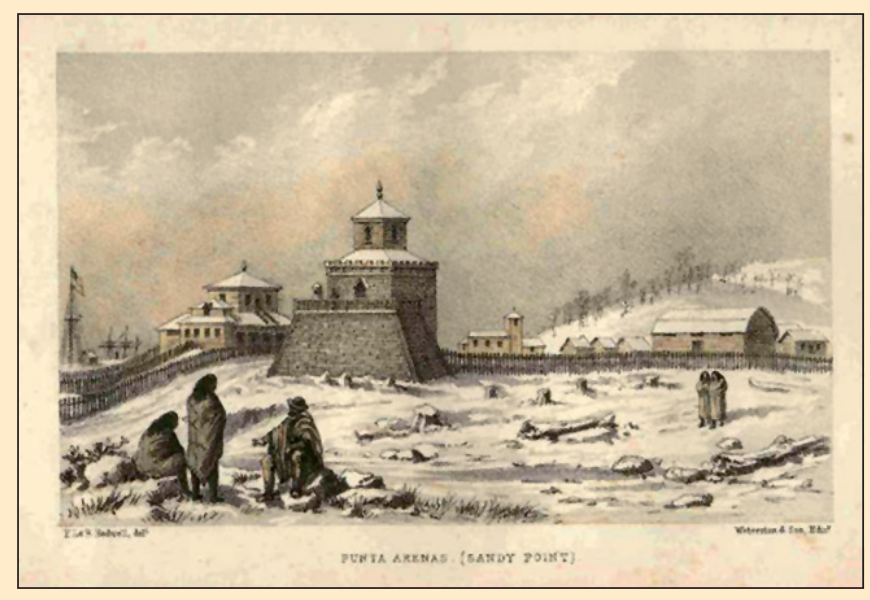

Figura 5. La Colonia de Punta Arenas hacia 1850.

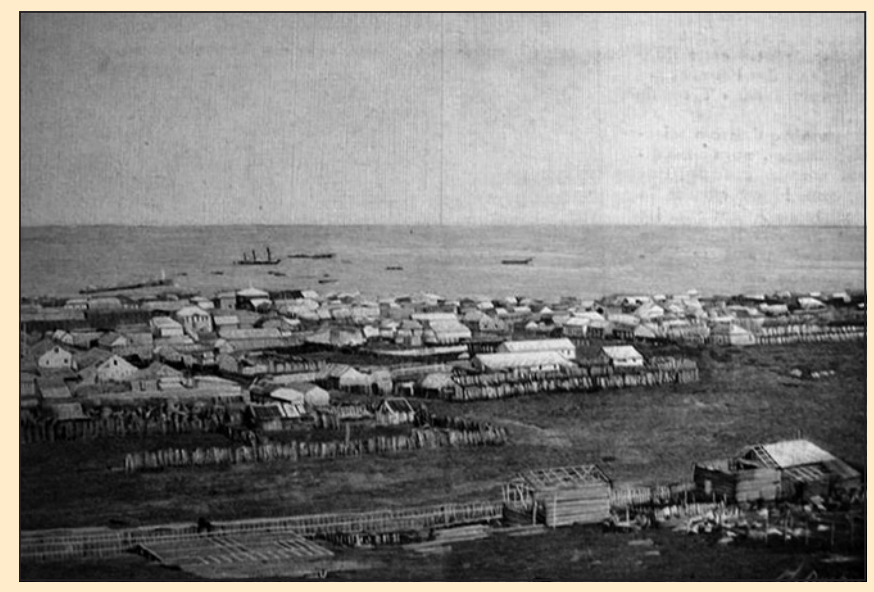

Figura 6. Punta Arenas en 1892.

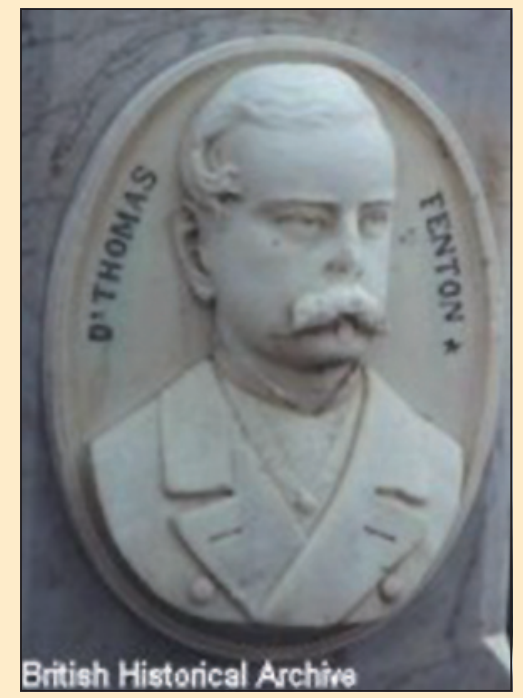

Figura 7. Dr. Thomas Fenton. 


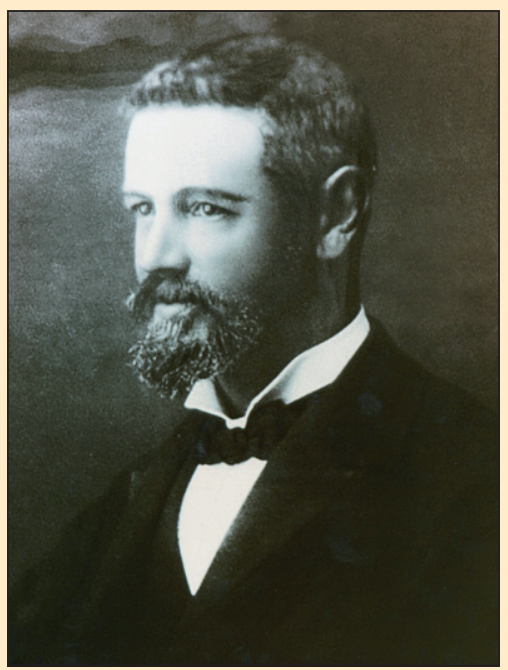

Figura 8. Dr. Lautaro Navarro Avaria.

Navarro (Figura 8), refrendaba lo anterior en documento citado por Martinic:... no hay agua ni por cañerías $n i$ corriente. Las letrinas están excavadas a pocos metros de los pozos de agua para beber, i a pesar de esta pésima condición no hai enfermedades como fiebres tifoideas, disenterías, etc. No se ha demostrado aqui el cólera asiático pues no ha habido un solo caso ${ }^{8,9}$.

Sin duda se estaba en lo que llamaríamos "expectación armada". Se temía que, si no se hacía algo para mejorar la higiene ambiental, sobrevendría algo pavoroso. Tenían razón, pero las terribles enfermedades vendrían, con el cambio de siglo, no por el agua sino por el aire.

El Gobernador Manuel Señoret, de controvertida actuación, como veremos, en el manejo de la cuestión indígena, hacia fines de ese siglo XIX impulsaba una serie de obras de progreso, entre las cuales no estaba exento el tema sanitario. Relata Robustiano Vera: Se dotó a la población con cañería de agua potable. (...) La prostitución se reglamentó, haciendo obligatorios los certificados médicos, para estirpar en lo posible las enfermedades venéreas. Luego se instauraría en la localidad de Agua Fresca, unos 30 kilómetros al sur de Punta Arenas, una Estación Sanitaria (...) que evite la introducción i propagación de las enfermedades de carácter infeccioso que puedan traernos los buques que vienen del Atlántico. Por las dificultades de acceso, en la práctica sólo se podía llegar por mar, lo que le hacía parecer más un destierro que un aislamiento sanitario. Pese a permanecer abierto durante 3 años nunca se llegó a ocupar. En 1906, con ocasión de una epidemia de viruela se abriría otro en Bahía Catalina, razonablemente más próximo a la Punta Arenas de entonces ${ }^{8,9}$.

Para mayor información sobre las enfermedades infectocontagiosas, especialmente infantiles, hasta fines del siglo XIX, me remito a los datos recogidos por Mateo Martinic:
La temida tuberculosis fue por fortuna de rara ocurrencia. (...) En cuanto a epidemias sólo cabe consignar una de alfombrilla (sarampión) registrada en 1866 y que llevó a una decena de niños a la tumba, cifra por demás alarmante para la exigua población colonial de la época. La misma enfermedad se repitió con mayor grado de violencia en $1889^{9}$.

El semanario "El Reloncaví" de Puerto Montt, citado por Martinic y refiriéndose a la epidemia de sarampión de 1889, relataba: La epidemia de alfombrilla (...) ya ha disminuido notablemente por la sencilla razón de que mui pocas familias o personas han escapado a ella. Sin embargo ha ocasionado no menos de 40 a 45 defunciones. Por supuesto que el mayor tributo lo han pagado las familias pobres, que por falta de recursos y su escasez de conocimientos hijiénicos carecían de los medios para atender bien a sus enfermos. Puede decirse que de las familias acomodadas no ha habido ninguna pérdida 9 .

Refiere también Mateo Martinic que "En 1890 se presentó una epidemia de coqueluche o tos convulsiva, y en 1894 una de viruela, por suerte ambas relativamente benignas".

En la segunda parte de esta revisión intentaremos analizar la influencia de las enfermedades infecciosas sobre la extinción de los pueblos originarios y la situación sanitaria de Magallanes durante el siglo XX, con especial énfasis en el modo que se afectaron los niños en ambos temas.

\section{Resumen}

Se revisan los antecedentes históricos de las enfermedades infecciosas de la infancia en la Región de Magallanes, con especial énfasis en su incidencia sobre la mortalidad infantil. Para efectos de su publicación, se divide el trabajo en dos partes. En esta primera parte se hace una somera relación de los hechos que llevaron a la muerte a casi todos los colonizadores españoles del Estrecho de Magallanes, incluyendo a los niños (15841590); a continuación se hace una descripción de los datos disponibles sobre las enfermedades infecciosas que afectaban a los aborígenes australes antes del contacto con el hombre blanco. Finalmente se describe la situación sanitaria de Punta Arenas, desde la fundación de Fuerte Bulnes hasta las postrimerías del siglo XIX.

\section{Referencias bibliográficas}

1.- Martinic M. La medicina y las enfermedades durante el ciclo histórico de los viajes de descubrimientos y exploraciones (principios del siglo XVI hasta mediados del siglo XIX). En: la medicina en Magallanes. Noticias y consideraciones para su historia. Ed. La Prensa Austral, 2 ${ }^{\mathrm{a}}$ Ed. 2010.

2.- Vieira M. Aquí estuvo España: aspectos sanitarios de la 
colonización española en el Estrecho de Magallanes. An Hist Med 2013 (Inédito, aceptado para publicación).

3.- Domínguez R. La pista médica del desastre de la expedición de Sarmiento de Gamboa al Estrecho de Magallanes.

Magallania (Chile) 2011; 39 (2): 5-13.

4.- Martinic M. Desde la prehistoria hasta el tiempo del contacto con los foráneos. En: la medicina en Magallanes. Noticias y consideraciones para su historia. Ed. La Prensa Austral, $2^{\mathrm{a}}$ Ed. 2010.

5.- Vieira M. La pediatría de los Selknam. Rev Chil Pediatr 2006; 77 (3): 237-8.

6.- Cooper J. Analytical and critical bibliography of the tribes of Tierra del Fuego and adjacent territory. Smithsonian Institution. Bureau of American Ethnology, Bulletin 63. Washington Government Printing Office, 1917.

7.- Gusinde M. Los indios de la tierra del fuego. Centro de Etnología Americana de Buenos Aires, Ed. 1982.

8.- Vera R. La colonia de Magallanes y Tierra del Fuego (1843-1897). Santiago de Chile, Imprenta de la Gaceta, Ed. 1897.

9.- Martinic M. La salud pública en la colonia de Magallanes (1843-1894). En: la medicina en Magallanes. Noticias y consideraciones para su historia. Ed. La Prensa Austral, $2^{\mathrm{a}}$ Ed. 2010.

\section{Anecdotario Infectológico}

\section{Zoonosis en el hogar}

\section{A zoonosis outbreak at home}

U na niña de 2 años 5 meses consultó por presentar los 4 días previos deposiciones semilíquidas y el día anterior fiebre, deposiciones con moco, sangre, y dolor abdominal. En la evaluación médica no hubo mayores hallazgos semiológicos. Solicitados exámenes generales de sangre y deposiciones, se le indicó medidas dietéticas y probióticos con el diagnostico de síndrome disentérico. Su evolución fue rápidamente favorable.

Días más tarde se obtuvo informe del coprocultivo el que describía desarrollo de Salmonella Poona (Grupo G), diagnóstico certificado por el I.S.P., Laboratorio Nacional de Referencia. Reevaluada la paciente se encontraba asintomática, como también sus padres y hermano. Se solicitó un nuevo coprocultivo de la paciente y en su hermano, resultando ambos negativos.

Indagando sobre la existencia de mascotas en el hogar, la madre recordó la llegada a casa de dos pequeñas tortugas acuáticas, pocos días antes del inicio del cuadro febril en su hija. La breve vida de las tortugas terminó cuando el perro de la casa las devoró en un momento de descuido. Un par de días después el perro enfermó brevemente, presentando deposiciones semilíquidas con sangre lo cual fue atribuido por los padres a la ingesta de la caparazón de las tortugas. Antes de ser llevado a un veterinario el perro mejoró espontáneamente y no fue estudiado microbiológicamente.

Contribución de Guillermo Vargas Brugues

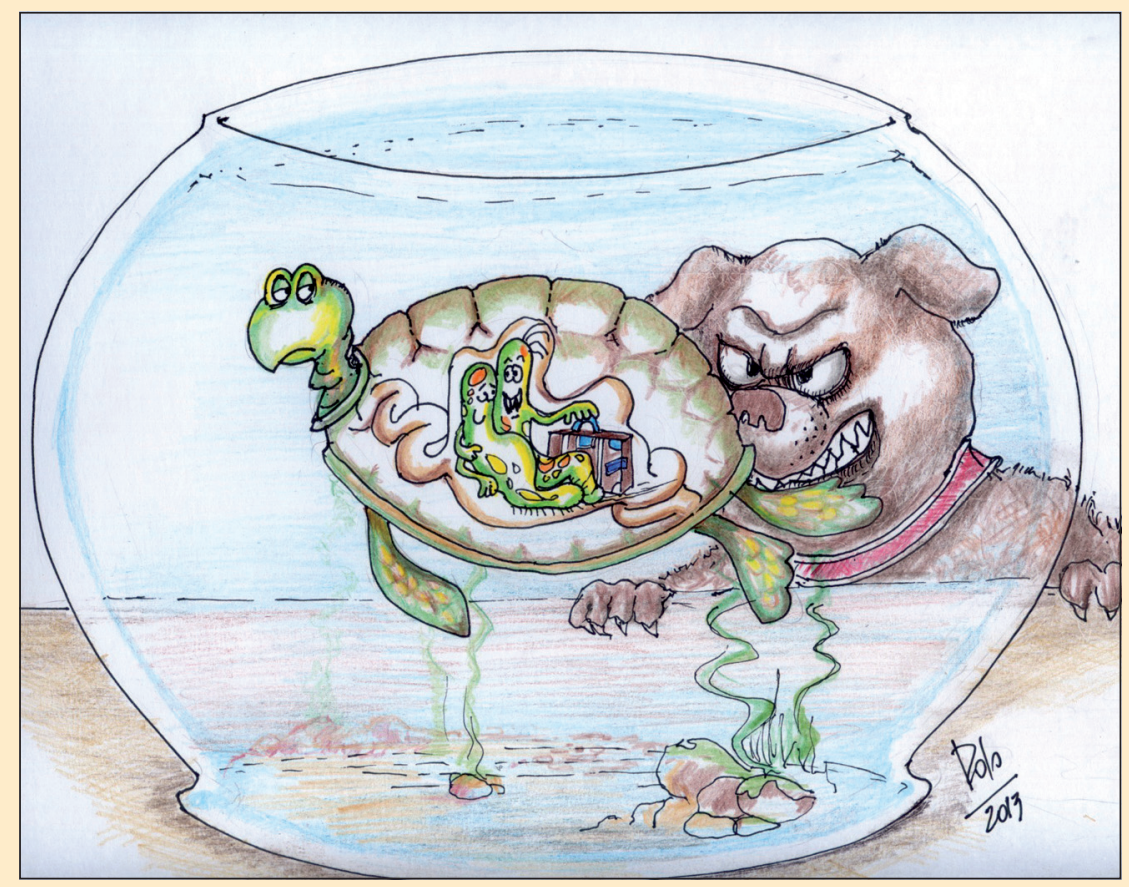

